\title{
Trends in hospital admissions for conditions associated with child maltreatment, Northern Territory, 1999-2010
}

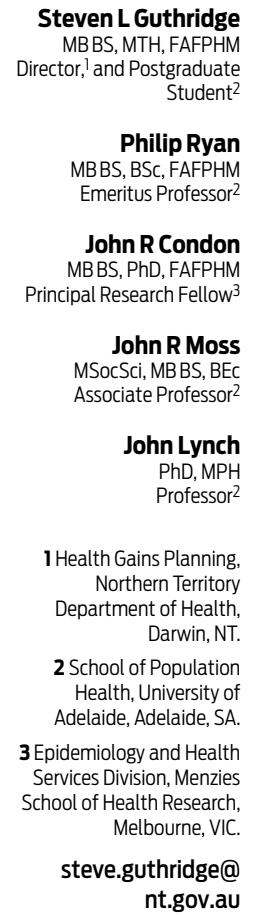

MJA 2014; 201: 162-166 doi: 10.5694/mjal4.00015

Editorial p 126

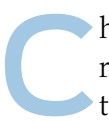

hild maltreatment statistics are routinely reported by child protection services in all Australian jurisdictions. ${ }^{1}$ There are well documented variations in both the rates and trends of these statistics among states and territories. In the 6 years from 2004-05 to 2009-10, notifications of possible maltreatment increased fourfold in Western Australia but halved in Queensland. For the same period, the number of substantiated cases halved in the Australian Capital Territory but increased threefold in the Northern Territory. ${ }^{1}$ Explanations for the variation both within and between jurisdictions include: varying mandatory reporting requirements; changes in the threshold for documenting reports; changes in definitions; and changes in policy and service capacity. ${ }^{2}$ Rates also vary between countries. The rate for Australian children subject to substantiated maltreatment was 6.1 per 1000 in 2009-10,1 compared with 14.2 per 1000 in Canada in $2008^{3}$ and 3.6 per 1000 children in England in 2009-10.4 Improved understanding of variations in child maltreatment rates is important in informing the rational development of services and has led to efforts to expand the sources of information used for child maltreatment surveillance. One possible source is hospital inpatient data.

Details of hospital admissions are coded by trained administrative staff using the International Classification of Diseases, which includes version 9, clinical modification (ICD-9-CM) and version 10, Australian modification (ICD-10-AM).5,6 The classification system includes codes for specific diagnoses and for cause of injury, including whether an injury was intentional. There are also codes for child maltreatment. A recent review of 47 international studies assessed the utility of hospital codes for reporting injury-related child maltreatment. ${ }^{7}$ The authors were guarded in their recommendation for the general use of hospital admissions data for reporting

\section{Abstrac}

Objective: To use hospital admissions data to investigate trends in maltreatment among Northern Territory Aboriginal and non-Aboriginal children.

Design, setting and participants: A historical cohort study using diagnosis and external cause codes from hospital admissions among children aged 0-17 years.

Main outcome measures: Annual rates of admission with either a definitive or indicative code for child maltreatment.

Results: From 1 January 1999 to 31 December 2010, the average annual rates of hospital admission of NT Aboriginal and non-Aboriginal children with a definitive code of maltreatment were $8.8(95 \% \mathrm{Cl}, 7.4-10.2)$ and $0.91(95 \% \mathrm{Cl}, 0.59-1.22)$ per 10000 children, respectively. There was no evidence for change over time in either population. The corresponding rates of admission with a code indicative of maltreatment were $28.4(95 \% \mathrm{Cl}, 25.8-31.1)$ and $5.2(95 \% \mathrm{Cl}, 4.4-6.0)$ per 10000 children, with average annual increases of $3 \%$ (incidence rate ratio [IRR], 1.03; 95\% Cl, 1.00-1.07) and 4\% (IRR, 1.04; 95\% Cl, 0.96-1.11). Physical abuse was the prominent type of maltreatment-related admission in both populations. There were increases in rates of admission for older Aboriginal children (13-17 years) and older non-Aboriginal boys. Most perpetrators in the assault of younger children were family members, while among older children most were not specified.

Conclusion: Our study shows the utility of hospital admissions for population surveillance of child maltreatment. The relatively stable rate of maltreatmentrelated hospital admissions among NT Aboriginal children shown here is in contrast to substantial increases reported from child protection data. The results also highlight the overlap between violence within families and in the wider community, particularly for older children, and lends support for population-level interventions to protect vulnerable children.

child maltreatment, concluding that the primary benefit was to identify "selected diagnoses" and patterns of child abuse.

The use of hospital data for more general surveillance has been uncommon. A 2004 analysis linked child protection data with diagnostic data from emergency departments and hospital admissions. ${ }^{8}$ The analysis identified $12 \%$ more cases of maltreatment than child protection data alone. Nonetheless, the authors concluded that the method was of only marginal benefit, and could not be justified as an ongoing model because of the limited subset of additional cases, methodological complexity and expense. More recently, it has been proposed that population surveillance may be feasible if based on a wider range of codes "suggestive" of child maltreatment. 9 Researchers identified 68 ICD9-CM codes which, when restricted by age bounds, were estimated to have a greater than $66 \%$ likelihood of being the result of child maltreatment. In WA, hospital maltreatment and assault codes have been validated by linkage with child protection data. ${ }^{10}$ The authors of this study subsequently reported long-term trends in child maltreatment and assault. ${ }^{11}$ WA hospital data were also used in a comparison of trends in maltreatment in six countries. ${ }^{12} \mathrm{~A}$ further variation in approach involved systematically identifying ICD-10-AM hospital inpatient codes "indicative" of child maltreatment. ${ }^{13}$ This approach included separate codes for four types of maltreatment - physical abuse, sexual abuse, emotional abuse and neglect. The application of these codes included a filter for specified perpetrator categories that may be recorded within admission codes.

We recently reported trends in notifications and substantiated cases of child maltreatment for the NT using child protection data for 1999 to $2010 .{ }^{14}$ Through this period of legislative 
1 Trends in hospital admission rates for child maltreatment, using both definitive and indicative codes (by type of maltreatment), 1999-2010

No. of Average annual rate Annual change in admissions per $10000(95 \% \mathrm{CI})$ rate, IRR $(95 \% \mathrm{CI})$

\begin{tabular}{lccc}
\hline $\begin{array}{l}\text { Aboriginal children } \\
\text { Definitive codes (1999-2010) }\end{array}$ & 275 & $8.8(7.4-10.2)$ & $0.96(0.91-1.01)$ \\
Indicative codes (1999-2010) & & & \\
$\quad$ Neglect & 170 & $5.5(4.7-6.3)$ & $1.03(0.96-1.11)$ \\
$\quad$ Physical abuse & 747 & $24.0(21.5-26.5)$ & $1.04(1.01-1.08)$ \\
$\quad$ Sexual abuse & 97 & $3.1(2.3-3.9)$ & $1.05(0.96-1.16)$ \\
Other* & 132 & $4.2(2.6-5.9)$ & $0.86(0.79-0.93)$ \\
All admissions & 885 & $28.4(25.8-31.1)$ & $1.03(1.00-1.07)$ \\
Non-Aboriginal children & & & $0.92(0.77-1.10)$ \\
Definitive codes (1999-2010) & 38 & $0.91(0.59-1.22)$ & \\
Indicative codes (1999-2010) & & & $1.01(0.73-1.39)$ \\
Neglect & 11 & $0.26(0.05-0.48)$ & $1.06(0.98-1.14)$ \\
Physical abuse & 188 & $4.5(3.5-5.4)$ & $0.98(0.81-1.21)$ \\
Sexual abuse & 27 & $0.6(0.4-0.9)$ & $0.83(0.66-1.06)$ \\
Other* & 25 & $0.6(0.3-0.9)$ & $1.04(0.96-1.11)$ \\
All admissions & 217 & $5.2(4.4-6.0)$ &
\end{tabular}

change, service expansion and continued media attention, the rate of substantiated cases of maltreatment increased by $18 \%$ per year among Aboriginal children, while there was no evidence of increase among nonAboriginal children. Despite the increase in substantiated cases, we were unable to identify whether there had been a change in the underlying rates of maltreatment in the population. The aim of this study was to investigate trends in child maltreatment among NT Aboriginal and non-Aboriginal children using a different data source - hospital admissions.

\section{Methods}

\section{Data sources}

We used the NT hospital separations dataset (HSD), which contains data (with coded diagnoses and procedures) for inpatient episodes for all five NT public hospitals. Data from the one private hospital in the NT were not available. The research dataset contained de-identified demographic information and up to 10 admission codes for all children aged $0-17$ years admitted between 1993 and 2010. Demographic information included a unique identification number for each child. Rates were calculated using population data (by year, sex, 5-year age-group and Indigenous status), provided by the Health Gains Planning Branch of the NT Department of Health, based on Australian Bureau of Statistics estimates. ${ }^{15}$

\section{Identification and classification of abuse-related episodes}

Hospital admissions were coded using the ICD-9-CM until June 1998 and then ICD-10-AM from July 1998 onwards. Analysis was undertaken using both the definitive codes for maltreatment (ICD-10-AM codes T74.0, Y06 and Y07 and ICD-9-CM codes 9955, E9684 and E967) and indicative codes proposed by McKenzie and Scott (Appendix; online at mja.com.au). ${ }^{13}$ Mapping of ICD-9-CM to ICD-10AM codes was possible for definitive maltreatment codes; ${ }^{16}$ however, there was an anomalous surge in ICD-9-CM coded episodes after 1996 which was consistent with a systematic change in coding practice. There was greater difficulty mapping the indicative codes, with one-to-many mapping of the indicative codes between ICD versions. As a result of these inconsistencies, the final analysis was restricted to the 12-year period from 1 January 1999 to 31 December 2010. Interstate residents, patients with no diagnostic information and "statistical discharges" were excluded. A statistical discharge indicates a change in the type of care during a single admission in the same hospital.
A number of changes were necessary to the approach of McKenzie and Scott.13 Supplemental codes for perpetrators were introduced for external cause codes (ICD-10-AM codes X85-Y09) in 2002, after commencement of the study period, and were therefore not used in the general analysis. McKenzie and Scott also included two procedure codes which were not included in this analysis. There were no recorded episodes of physical abuse counselling (9608400) in the NT HSD, while the small number of full-body radiography procedures (5830600) not already identified using an admission code for child maltreatment were commonly associated with conditions such as the assessment of cancer or genetic conditions.

Repeat admissions of a child for the same incident, including interhospital transfers, were identified using separation mode, date of separation and admission codes. These admissions were then analysed as a single event based on details provided for the first admission.

\section{Analysis}

The incidence rates for all maltreatment-related hospitalisation episodes were calculated by Indigenous status for the age-group 0-17 years combined; a subanalysis for physical abuse-related hospitalisations included sex and age-specific (0-12 and 13-17 years) rates. Poisson regression was used to estimate the incidence rate ratio for the annual increase in rates by calendar year.

\section{Ethics}

The study protocol was approved by the Human Research Ethics Committee of the NT Department of Health and the Menzies School of Health Research (HREC 11-1501) and the Human Research Ethics Committee of the University of Adelaide (H-028-2011).

\section{Results}

The study dataset contained information on 150962 public hospital admissions, from 1999 to 2010. Analysis was undertaken on 140646 records after excluding 6857 interstate residents, 90 patients with no diagnostic information and 3369 statistical discharges. 


\section{Definitive maltreatment diagnoses}

There were 323 admissions with at least one definitive code for maltreatment. After removing 10 repeat admissions there were 275 admissions of Aboriginal children and 38 admissions of non-Aboriginal children (Box 1). The average annual hospitalisation rate for Aboriginal children with a definitive code was almost ten times the rate for non-Aboriginal children (8.8 v 0.91 admissions per 10000 per year, respectively). The rate for each group tended to decrease over time, but neither decrease was statistically significant.

\section{Indicative maltreatment diagnoses}

During the same period, there were 1201 admissions with one or more codes indicative of maltreatment. After removing 99 repeat admissions, there remained 885 admissions of Aboriginal children and 217 admissions of non-Aboriginal children (Box 1). The average annual hospitalisation rate was greater for Aboriginal children than non-Aboriginal children (28.4 v 5.2 admissions per 10000 per year, respectively). Between 1999 and 2010, the estimated hospitalisation rate increased by $3 \%$ for Aboriginal and $4 \%$ for non-Aboriginal children, but the $95 \%$ confidence intervals were also consistent with no change or a small decrease (non-Aboriginal children) over time.

There was an overlap between types of maltreatment, with some children being diagnosed on the same admission with more than one type of maltreatment. Physical abuse was reported for about $85 \%$ of admissions for maltreatment among both Aboriginal and non-Aboriginal children (Box 1). The hospitalisation rate for Aboriginal children was almost five times the rate for non-Aboriginal children; rates increased for both groups between 1999 and 2010 (by $4 \%$ and $6 \%$ per year, respectively). The increase for Aboriginal children was statistically significant. For the group of non-specific indicative codes ("other"), including emotional abuse, the hospitalisation rate decreased by $14 \%$ per year for Aboriginal children and $17 \%$ per year for nonAboriginal children. The decrease for Aboriginal children was statistically significant (but may reflect a shift in
2 Trends in hospital admission rates for children with a diagnosis indicative of physical abuse, 1999-2010

\begin{tabular}{|c|c|c|c|}
\hline $\begin{array}{l}\text { No. of } \\
\text { dmissions }\end{array}$ & $\begin{array}{l}\text { Average annual rate } \\
\text { per } 10000(95 \% \mathrm{Cl})\end{array}$ & $\begin{array}{c}\text { Rate ratio } \\
\text { (Aboriginal v } \\
\text { non-Aboriginal) }\end{array}$ & $\begin{array}{l}\text { Annual cha } \\
\text { rate, IRR (95 }\end{array}$ \\
\hline
\end{tabular}

\begin{tabular}{|c|c|c|c|c|}
\hline \multicolumn{5}{|c|}{ Aboriginal children } \\
\hline \multicolumn{5}{|l|}{ Boys } \\
\hline $0-12$ years & 104 & $8.8(6.7-10.8)$ & 4.1 & $1.01(0.96-1.07)$ \\
\hline 13-17 years & 237 & $58.2(49.4-67.1)$ & 3.1 & $1.04(1.01-1.06)$ \\
\hline \multicolumn{5}{|l|}{ Girls } \\
\hline $0-12$ years & 81 & $7.2(5.9-8.5)$ & 8.9 & 0.99 (0.94-1.06) \\
\hline $13-17$ years & 325 & $82.8(69.2-96.3)$ & 13.5 & $1.07(1.05-1.09)$ \\
\hline \multicolumn{5}{|c|}{ Non-Aboriginal children } \\
\hline \multicolumn{5}{|l|}{ Boys } \\
\hline $0-12$ years & 34 & $2.1(1.1-3.1)$ & & $1.11(0.99-1.25)$ \\
\hline 13-17 years & 110 & $19.0(14.8-23.2)$ & & 1.05 (1.01-1.09) \\
\hline \multicolumn{5}{|l|}{ Girls } \\
\hline $0-12$ years & 12 & $0.8(0.4-1.3)$ & & $1.06(0.88-1.28)$ \\
\hline 13-17 years & 32 & $6.1(4.5-7.8)$ & & $1.01(0.94-1.08)$ \\
\hline
\end{tabular}

3 Perpetrator categories for all maltreatment, 2003-2010

Recorded perpetrator by category

\begin{tabular}{lccccc}
\multicolumn{5}{c}{ Recorded perpetrator by category } \\
\cline { 2 - 5 } & \multicolumn{1}{c}{ Spouse/partner } & Family member & Other & Unspecified & Total \\
\hline \multicolumn{2}{l}{ Aboriginal children } \\
0-12 years & $6(2.2 \%)$ & $192(70.3 \%)$ & $18(6.6 \%)$ & $57(20.9 \%)$ & 273 \\
$13-17$ years & $77(17.9 \%)$ & $80(18.6 \%)$ & $56(13.1 \%)$ & $216(50.3 \%)$ & 429 \\
All children & $83(11.8 \%)$ & $272(38.7 \%)$ & $74(10.5 \%)$ & $273(38.9 \%)$ & 702 \\
Non-Aboriginal children & & & & \\
0-12 years & $0(0)$ & $24(55.8 \%)$ & $5(11.6 \%)$ & $14(32.6 \%)$ & 43 \\
$13-17$ years & $1(1.0 \%)$ & $12(11.7 \%)$ & $25(24.3 \%)$ & $65(63.1 \%)$ & 103 \\
All children & $1(0.7 \%)$ & $36(24.7 \%)$ & $30(20.5 \%)$ & $79(54.1 \%)$ & 146
\end{tabular}

coding practice toward more specific codes).

The hospitalisation rate for conditions indicative of physical abuse was much higher for older children than younger children among both Aboriginal and non-Aboriginal children (Box 2). For non-Aboriginal children, the hospitalisation rate was 2-3 times as high for boys compared with girls in both age groups. Among Aboriginal children, the rates were similar for boys and girls aged 0-12 years, but higher for girls than boys among those aged 13-17 years, and increased for both older groups. The rate among older Aboriginal girls was 13.5 times the rate among older nonAboriginal girls (Box 2).

\section{Perpetrators}

The available data with perpetrator codes, for 2003-2010, showed that among younger children, both Aboriginal and non-Aboriginal, most perpetrators were family members
(Box 3). For most older children, a perpetrator was not specified. One notable difference among older children was that a spouse or partner was recorded as the perpetrator for $18 \%$ of Aboriginal children but only $1 \%$ of non-Aboriginal children.

\section{Discussion}

Our study shows the utility of hospital admissions data for population surveillance of child maltreatment. A direct comparison can be made between the results in this study and the results of our previous trend analysis, for the same period and same population, using child protection data. ${ }^{14}$ Among NT non-Aboriginal children there was a significant increase in notifications of possible maltreatment between 1999 and 2010, but both child protection substantiations and hospital admissions data suggest that the underlying level of child maltreatment has remained stable. Among 
Aboriginal children, the comparison of child protection and hospital data is more complex. Between 1999 and 2010, notifications to child protection authorities increased for all types of maltreatment, with an overall annual increase of $21 \%$. This was matched by an annual increase of $18 \%$ in rates of substantiated cases. Numbers of cases also increased by type of maltreatment, except for physical abuse. ${ }^{14}$ The current study shows no increase in definitive codes and a 3\% annual increase using the indicative codes, of uncertain significance. The difference in trends between data sources supports the argument that the increases in substantiated cases were a result of factors including improved identification, changes in policy and increased capacity in child protection services. The judgement by a clinician that a hospital admission was maltreatmentrelated involves a level of subjectivity, but the results suggest that clinical reporting practice did not change substantially over time.

Among older Aboriginal children, there was an increase in admission rates for physical abuse. Of particular concern was the violence against older Aboriginal girls, who had the highest rate of hospital admission for physical abuse among all groups, which was 13.5 times the rate for older nonAboriginal girls. Perpetrator coding was available for more recent years; and while for most admissions the perpetrator was not specified, those that were specified suggest that the violence against older children extended beyond the historical definition of maltreatment (involving only parents and caregivers) to violence within the broader community, including from peers and partners. The results are consistent with previous reports on interpersonal violence that have highlighted the increased risk among Aboriginal children and women. ${ }^{17-20}$

The study results also support a more general application. In WA, a maltreatment admissions rate of 2.7 per 10000 children was reported for 1999, falling to 1.3 per 10000 children in 2005.11 The WA rate in 2005 is consistent with the rate of 0.91 per 10000 for non-Aboriginal NT children reported in this study. The WA rate of assault-related hospitalisation was 6.1 per 10000 children in 2005,11 while for NT non-Aboriginal children in our study the average annual rate for physical abuse was 4.5 per 10000 children. There are variations in the methods, populations and the time periods between studies; however, the similarity of results indicates that hospital admissions may provide a more consistent basis for comparison between Australian states and territories than the current reliance on child protection reports.

Whether based on child protection sources or hospital admissions, child maltreatment rates are only indicators of the prevalence of child maltreatment in a community. Hospital admissions data have the further limitation of only containing a subset of more severe episodes of maltreatment. In particular, emotional abuse is a rare hospital diagnosis, but is commonly reported in child protection data. A second limitation is that reporting is entirely dependent on clinical records. Definitive codes have the requirement that they can only be applied if there is a clear statement within the clinical record that the episode is a consequence of maltreatment. Clinicians may be suspicious, but not certain, so an episode can pass without a definitive record. Despite recommendations for developing classifications, there is currently no diagnosis code for "possible" maltreatment.9,21 As a result of not being able to use perpetrator codes for the general analysis in this study, there will be an overestimate of maltreatment-related admissions. However, the study shows a converse difficulty that, even when available, the perpetrator code was not specified in a substantial proportion of admissions.

This study demonstrates that hospital admissions data can provide an additional source for surveillance of child maltreatment in a population. The use of hospital data is particularly useful among younger children where there is a clearer association with family-related incidents. In this study, the stable rate of maltreatment-related admissions in younger Aboriginal children was in contrast to the increase in substantiated cases reported by child protection services. ${ }^{14}$ For older children the codes indicative of maltreatment overlap with incidents within the wider community. The extent of violence and overlap of family and community incidents lends support to the calls for a broad population strategy, with focus on prevention, to protect vulnerable children. ${ }^{21,22}$

Acknowledgements: We thank senior managers in the NT Department of Children and Families and Department of Health for their support, and health staff for their diligence over many years in recording and maintaining NT hospital admissions information and for the preparation of the research dataset. Steven Guthridge conducted the project during a period of salaried leave from the NT Government. John Lynch was supported by a National Health and Medical Research Council Australia Fellowship 570102.

Competing interests: No relevant disclosures.

Received 4 Jan 2014, accepted 14 May 2014.

1 Australian Institute of Health and Welfare. Child protection Australia 2009-10. Canberra: AlHW, 2011. (AlHW Cat. No. CWS 39; Child Welfare Series No. 51.)

2 Holzer P, Bromfield L. NCPASS comparability of child protection data: project report. Melbourne: National Child Protection Clearinghouse, Australian Institute of Family Studies, 2008.

3 Public Health Agency of Canada. Canadian incidence study of reported child abuse and neglect - 2008: major findings. Ottawa: Public Health Agency of Canada, 2010.

4 Department of Education, UK. Children in need in England, including their characteristics and further information on children who were the subject of a child protection plan (2009-10 Children in Need census - Final). England: Department of Education, 2010.

5 National Center for Health Statistics. International classification of diseases, 9th revision, clinical modification (ICD-9-CM). 7th ed. United States: Commission of Professional and Hospital Activities, 1990.

6 National Centre for Classification in Health. International statistical classification of diseases and related health problems, 10th revision, Australian modification (ICD-10-AM). 7th ed. Tabular list of diseases and alphabetic index of diseases. Sydney: NCCH, 2010.

7 Scott D, Tonmyr L, Fraser J, et al. The utility and challenges of using ICD codes in child maltreatment research: a review of existing literature. Child Abuse Negl 2009; 33: 791-808.

8 Schnitzer PG, Slusher P, Van Tuinen M. Child maltreatment in Missouri: combining data for public health surveillance. Am J Prev Med 2004; 27: 379-384.

9 Schnitzer PG, Slusher PL, Kruse RL, Tarleton MM. Identification of ICD codes suggestive of child maltreatment. Child Abuse Negl 2011; 35: 3-17.

10 O'Donnell M, Nassar N, Leonard HM, et al. The use of cross-jurisdictional population data to investigate health indicators of child maltreatment. Med J Aust 2010; 193: 142-145.

11 O'Donnell M, Nassar N, Leonard H, et al. Monitoring child abuse and neglect at a population level: patterns of hospital admissions for maltreatment and assault. Child Abuse Negl 2010; 34: 823-832.

12 Gilbert R, Fluke J, O'Donnell M, et al. Child maltreatment: variation in trends and policies in six developed countries. Lancet 2012; 379: 758-772.

13 McKenzie K, Scott DA. Using routinely collected hospital data for child maltreatment surveillance: issues, methods and patterns. BMC Public Health 2011; $11: 7$ 
14 Guthridge SL, Ryan P, Condon, et al. Trends in reports of child maltreatment in the Northern Territory, 1999-2010. Med J Aust 2012; 197: 637-641.

15 Department of Health and Families. Northern Territory resident population estimates by age, sex, Indigenous status and health district (19712010). Darwin: NT Government, 2011.

16 National Casemix and Classification Centre (NCCC). ICD-9-CM - ICD-10-AM first edition mapping tables. NCCC, University of Wollongong, 1998. https://nccc.uow.edu.au/ icd10am-achi-acs/icd10ammappingtables/ index.html (accessed Apr 2014).
17 Meuleners LB, Lee AH, Hendrie D. A populationbased study of repeat hospital admissions due to interpersonal violence for children aged $0-9$ years. Paediatr Perinat Epidemiol 2009; 23: 239-244.

18 Meuleners LB, Lee AH, Hendrie D, Fraser M. A population study on Indigenous hospitalisations for interpersonal violence. Aust Health Rev 2010; 34: 123-126.

19 Berry JG, Harrison JE, Ryan P. Hospital admissions of Indigenous and non-Indigenous Australians due to interpersonal violence, July 1999 to June 2004. Aust N Z Public Health 2009; 33: 215-222.
20 Australian Institute of Health and Welfare. Family violence among Aboriginal and Torres Strait Islander peoples. Canberra: AlHW, 2006. (AlHW Cat. No. IHW 17.)

21 McKenzie K, Scott DA, Waller GS, Campbell M. Reliability of routinely collected hospital data for child maltreatment surveillance. BMC Public Health 2011; 11: 8.

22 O'Donnell M, Scott D, Stanley F. Child abuse and neglect - is it time for a public health approach? Aust N Z Public Health 2008; 32: 325-330. 